Overall this book is a good comprehensive guide to contemporary management in the NHS and it will be invaluable in teaching and supervising trainees and for recently appointed clinical directors. Although there is some overlap in the content, this allows consideration of different approaches. However, a looseleaf format might have facilitated updating. Consider how quickly the $\mathrm{CHI}$ has come and gone!

The use of this guide will facilitate the cultural shift necessary to allow the consistent and dependable delivery of high quality services, which is at the heart of clinical governance.

Nicholas Brown Birmingham and Solihull Menta Health Trust, Lyndon Clinic, Hobs Meadow, Solihull B92 8PW, e-mail: n.brown47@btinternet.com

\title{
miscellany
}

\section{The Sarah Isabella McClean Will Trust}

The Sarah Isabella McClean Will Trust exists to alleviate the suffering or assist in the recovery of medical practitioners in need suffering from mental illness who require hospital treatment by providing or paying for items, services or facilities not readily available to them from other sources.

The trustees meet annually and at other times as necessary to review the charity's finances and requests for assistance from potential beneficiaries.

Contact details for the trustees are:
Dr G. C. Finlayson Consultant Psychiatrist, Bradford District CareTrust, The Moor Lane Centre, Moor Lane, Burley-in-Wharfedale LS29 7AJ, tel: 01943 862031,

Dr R. F. Kehoe Medical Director, Cygnet Hospital at Wyke, Blankney Grange, Huddersfield Road, Lower Wyke, Bradford BD12 8L5, tel: 01274605500 ,

Mr E.V. Brown Ford \& Warren Solicitors, Westgate Point, Westgate, Leeds LS1 2AX, tel: 01132436601

\section{forthcoming events}

Applications are invited for Semester One of the MRCPsych course run by University College London (UCL). Part I takes place on Monday afternoons commencing 4 September 2006 and Part II takes place on Tuesday afternoons commencing 5 September 2006. The course has been updated in keeping with the Royal College of Psychiatrists' syllabus and includes mock exams, theme-specific revision sessions and patient perspectives. For further information and an application form please contact Lydia M. Clinton, Course Administrator (tel: 0207679 9475; e-mail: mrcpsych@ucl.ac.uk).

The UCL Department of Mental Health Services invites applications for a 2-year, part-time MSc in Psychiatric Research starting in October 2006. The MSc is intended for senior house officers and specialist registrars in psychiatry and provides practical training in the relevant research skills. All teachers on the course are very active as researchers, and students report that the course is enjoyable and highly relevant to developing the skills needed to be an independent researcher. Our aim is to equip graduates to carry out research at doctoral level and apply for research posts in university departments. The first year consists of workshops and seminars on research skills, held on Monday afternoons. Topics include literature reviews and metaanalysis, design and selection of research instruments, epidemiology, evaluation of interventions, qualitative research methods, biological research and statistics. In the second year students undertake a research project under supervision and submit a dissertation. Early application is advisable as places are limited. For an application form and prospectus please contact Lydia M. Clinton, Course Administrator (tel: 0207679 9475; e-mail: mrcpsych@ucl.ac.uk). To discuss the course please contact the course tutor Dr Sonia Johnson (s.johnson@ucl.ac.uk).

The Schizophrenia Research Foundation (SCARF), the Indian Psychiatric Society and the World Psychiatric Association would like to announce the International Conference on Schizophrenia 2006 to be held in Chennai, India on 13-15 October 2006. The theme of the conference is 'Blending schizophrenia care with research: global perspectives'. This conference will showcase the best of schizophrenia research around the world and will cover a wide range of topics which have an impact on care, rehabilitation and policies and programmes for those with mental illness and disability. For further information please visit http:// www.icons-scarf.org

\section{The 6th International Forum On Mood} and Anxiety Disorders will take place from Wednesday 29 November to Friday 1 December 2006 in Vienna, Austria. Topics will include treatment-resistant depression, bipolar depression, recent advances in depression, chronic insomnia and mood and anxiety disorders in old age. For further information visit http:// www.aim-internationalgroup.com/2006/ ifmad

The 2nd International Congress of the World Federation of Societies of Biological Psychiatry will take place in Santiago de Chile from 17 to 21 April 2007. In the past 2 years there has been ground-breaking progress in neuroscience that is changing concepts of and attitudes towards psychiatric illness. Advances in biology and molecular genetics, the availability of modern technologies, such as brain neuroimaging, and the development of a new generation of treatments based upon concepts of neuroplasticity are opening new and exciting horizons. During the congress there will be opportunity to discuss these themes as well as the integration of the rapid development of scientific knowledge with its impact on diagnosis, treatment and rehabilitation of patients with mental illness. For further information visit http://www.wfsbpsantiago2007.org 